\title{
Comunicação
}

\section{Enraizamento de estacas apicais de figueira Roxo de Valinhos submetidas à estratificação a frio úmido e AIB}

\author{
Rafael Pio ${ }^{1}$, Tatiane Ohland ${ }^{2}$ Edvan Alves Chagas ${ }^{3}$, Wilson Barbosa ${ }^{4}$, Idiana Marina Dalastra 5 , \\ Marcelo Angelo Campagnolo ${ }^{6}$, José Emílio Bettiol Neto ${ }^{7}$
}

\section{RESUMO}

Na produção de mudas de figueira a utilização de estacas apicais de menor comprimento pode facilitar o manejo no viveiro, entretanto ainda não foram definidos os protocolos para enraizamento desse tipo de estaca. O objetivo do presente trabalho foi avaliar a ação da estratificação à frio úmido e do tratamento com AIB na rizogênese de estacas apicais de figueira Roxo de Valinhos. As estacas foram coletadas da porção apical dos ramos no final do período hibernal (julho) e padronizadas com $20 \mathrm{~cm}$ de comprimento e diâmetro aproximado de $0,7 \mathrm{~cm}$. As estacas foram estratificadas (estacas embrulhadas em jornal umedecido e protegidas com saco plástico à temperatura de $4{ }^{\circ} \mathrm{C}$, em câmara tipo BOD) por diferentes períodos (0, 15, 30, 45 e 60 dias) e, posteriormente, tratadas e não tratadas com 2.000 $\mathrm{mg} \mathrm{L}^{-1}$ de AIB por 10 segundos. Em seguida, as estacas foram enterradas em leito de areia umedecido sob telado constituído de tela de polipropileno preta (sombreamento de 50\%). Passados 60 dias de cada período de estratificação, foram mensuradas a percentagem de estacas enraizadas, a percentagem de estacas brotadas e o número médio de brotações e de raízes por estaca. Conclue-se que as estacas apicais de figueira Roxo de Valinhos estratificadas a frio úmido por 30 dias e posteriormente tratadas com $2.000 \mathrm{mg} \mathrm{L}^{-1}$ de AIB apresentaram maior potencial de rizogênese.

Palavras-chave: Ficus carica L., estaquia e ácido indolbutírico.

\section{ABSTRACT}

\section{Rooting of apical cuttings of fig plants cv. 'Roxo de Valinhos' treated with cold-humid stratification and IBA}

The objective of the present work was to evaluate the effects of cold-humid stratification and IBA on the rhizogenesis of apical cuttings of fig plants cv. 'Roxo de Valinhos'. Cuttings were collected from the apical portion of branches at the end of the dormant period (July), and standardized with $20 \mathrm{~cm}$-length and $0.7 \mathrm{~cm}$ diameter. The cuttings were stratified (cuttings wrapped in moist newspaper and protected with plastic bag at temperature of $4^{\circ} \mathrm{C}$, in BOD camera) for different periods (0, 15, 30, 45 and 60 days) and then, treated and nontreated with $2000 \mathrm{mg} \mathrm{L}^{-1}$ of IBA for 10 seconds. The treated cuttings were buried in sand moistened in the nursery

Recebido para publicação em julho de 2009 e aprovado em abril de 2010

'Engenheiro Agrônomo, Doutor. Universidade Federal do Paraná (UFPR), Rua dos Funcionários, 1540, Juvevê, 80035-050, Curitiba, Paraná, Brasil. Autor para correspondência. rafaelpio@hotmail.com

${ }^{2}$ Acadêmico Agronomia. Universidade Estadual do Oeste do Paraná (UNIOESTE), Rua Pernambuco, 1777, Caixa Postal 1008, 85960-000, Marechal Cândido Rondon, Paraná, Brasil. tatianeohland@hotmail.com

${ }^{3}$ Engenheiro Agrônomo, Doutor. Empresa Brasileira de Pesquisa Agropecuária (EMBRAPA CPAFRR), Rodovia 174, Km 8, Caixa Postal 133, 69301-970, Boa Vista, Roraima, Brasil.echagas@cpafrr.embrapa.br

${ }^{4}$ Biólogo, Mestre. Centro Experimental Central, Instituto Agronômico (IAC), Caixa Postal 28, 13001-970, Campinas, São Paulo, Brasil. wbarbosa@iac.sp.gov.br

${ }^{5}$ Engenheira Agrônoma, Mestre. Universidade Estadual Paulista Júlio de Mesquita Filho (UNESP), Faculdade de Ciências Agronômicas de Botucatu, Departamento de Produção Vegetal, Fazenda Experimental Lageado s/n, Caixa Postal 237, 18603970, Botucatu, São Paulo, Brasil. ididalastra@yahoo.com.br

${ }^{6}$ Biólogo. Universidade Estadual do Oeste do Paraná (UNIOESTE), Rua Pernambuco, 1777, Caixa Postal 1008, 85960-000, Marechal Cândido Rondon, Paraná, brasil. campa_bio@yahoo.com.br

${ }^{7}$ Acadêmico Agronomia. Instituto Agronômico (IAC), Av. Luiz Pereira dos Santos, 1500, Corrupira, 13214-820, Jundiaí, São Paulo, Brasil. bettiolneto@iac.sp.gov.br 
(50\% of brightness). After 60 days of each stratification period, cuttings were evaluated for the percentage of rooting, the percentage of sprouted cuttings, and the average number of shoots and roots per cutting. The results showed that apical cuttings of fig plants cv. 'Roxo de Valinhos' stratified in cold-humid for 30 days and subsequently treated with $2000 \mathrm{mg} \mathrm{L}^{-1}$ of IBA have greater rhizogenesis potential.

Key words: Cutting, Ficus carica L., indolbutyric acid.

\section{INTRODUÇÃO}

A propagação da figueira (Ficus carica L.) é realizada por meio de estacas caulinares lenhosas, aproveitando o material oriundo da poda hibernal, efetuada entre os meses de junho e julho (Alvarenga et al., 2007). Em vista da grande importância dessa cultura, observa-se que existem várias técnicas de manejo que precisam ser melhoradas, como o plantio das estacas diretamente na cova, em que são utilizadas estacas com dimensões de aproximadamente $40 \mathrm{~cm}$ de comprimento e diâmetro de três $\mathrm{cm}$. Essa prática vem acarretando elevado custo de implantação do pomar, devido ao baixo índice de enraizamento das estacas, por não haver coincidência da estaquia com o período chuvoso, principalmente nas regiões Sul e Sudeste, originando desuniformidade na formação do figueiral e, muitas vezes, necessidade de replantios (Chalfun \& Hoffmann, 1997; Gonçalves et al., 2003).

Uma opção seria o enraizamento prévio das estacas em ambiente protegido, sendo essa, uma forma alternativa e promissora na propagação da figueira, podendo-se assim utilizar estacas de menor comprimento, facilitando o manejo das mudas no viveiro, além de propiciar a seleção de plantas de qualidade e plantio no período chuvoso, possibilitando a obtenção de um pomar uniforme e vigoroso.

Segundo Pio et al. (2004), a utilização da porção apical dos ramos produtivos da figueira para o enraizamento propiciou bons resultados, comprovando-se a viabilidade da utilização de fragmentos de menores dimensões para a produção de mudas. Entretanto, no enraizamento das estacas sob telado constituído de sombrite com $50 \%$ de luminosidade houve aproximadamente $49 \%$ de enraizamento sem a utilização de ácido indolbutírico (AIB), aumentando esse percentual em $8 \%$ com a aplicação de $2000 \mathrm{mg} \mathrm{L}^{-1}$ do referido fitorregulador (Pio et al., 2006a).

Um método utilizado para aumentar o potencial de enraizamento das estacas lenhosas é a estratificação das estacas em leito de areia umedecido ou em baixa temperatura (inferior a $5^{\circ} \mathrm{C}$ ), técnica que possui como finalidade ausentar o material propagativo de luz ou então suprir a necessidade de frio, com o intuito de superar a endodormência das gemas e aumentar o enraizamento das estacas (Biasi, 1996). Associada à estratificação das estacas, a aplicação de fitorreguladores, no caso auxinas, permite aumentar a percentagem de enraizamento (Fachinello et al., 2005).

Nesse âmbito, pressupõe-se que a exposição das estacas apicais lenhosas de figueira à baixa temperatura, aliada ao tratamento com o AIB, promova incremento significativo na rizogênese das estacas apicais, aumentando o rendimento de mudas e minimizando o desperdício de propágulos. O objetivo do presente trabalho foi avaliar a ação da estratificação a frio úmido e o tratamento com AIB no enraizamento de estacas apicais da figueira Roxo de Valinhos.

\section{MATERIAL E MÉTODOS}

Estacas caulinares lenhosas apicais dos ramos da figueira Roxo de Valinhos, desprovidas de folhas, foram coletadas no final do período hibernal (julho) em um pomar comercial situado no município de Quatro Pontes, PR. As estacas foram transportadas imediatamente ao Setor de Fruticultura da Universidade Estadual do Oeste do Paraná (UNIOESTE), Marechal Cândido Rondon, PR, onde foram padronizadas com $20 \mathrm{~cm}$ de comprimento e diâmetro de $0,7 \mathrm{~cm}$. Efetuou-se também um corte em bisel na base da estaca e outro reto no ápice, com auxílio de tesoura de poda. Em seguida, as estacas foram lavadas em água corrente, banhadas em solução de oxicloreto de cobre à 0,3\% por cinco minutos e separadas em feixes com 80 estacas. Esses foram individualmente envolvidos por folhas de jornal umedecido, cuidadosamente amarrados e posteriormente colocados dentro de saco plástico preto, para evitar a perda de umidade. Os feixes permaneceram em estratificação à frio-úmido, à temperatura de $4{ }^{\circ} \mathrm{C}$, em câmara tipo BOD por 15, 30, 45 e 60 dias, além da testemunha sem estratificação.

Passado o período de estratificação, as estacas foram removidas da câmara e metade da sua base foi imersa em solução de AIB a $2.000 \mathrm{mg} \mathrm{L}^{-1}$ por 10 segundos. Em seguida, enterrou-se 2/3 de seu comprimento em leito de areia umedecido na posição vertical, em telado constituído de tela de polipropileno preta (sombreamento de 50\%). 
O delineamento adotado foi o inteiramente casualizado, em esquema fatorial 5 x 2, com quatro repetições e 10 estacas por unidade experimental, totalizando-se 400 estacas. Durante a condução do experimento, o leito de enraizamento foi irrigado manualmente duas vezes ao dia por meio de regador. Passados 60 dias de cada período de estratificação, foram mensurados a percentagem de estacas enraizadas, a percentagem de estacas brotadas e o número médio de brotações e de raízes por estaca.

Os dados foram submetidos à análise de variância, e as médias comparadas pelo teste Scott-Knott, a 5\% de probabilidade. As análises foram realizadas pelo programa computacional SISVAR.

\section{RESULTADOS E DISCUSSÃO}

De acordo com a análise estatística, houve interação entre o tempo de estratificação e o tratamento com AIB.

O tratamento com $2.000 \mathrm{mg} \mathrm{L}^{-1}$ de AIB incrementou a percentagem de estacas enraizadas e o número médio de raízes, independentemente do tempo de estratificação das estacas a frio úmido (Tabela 1). Esses resultados assemelham-se aos obtidos por Pio et al. (2004), que igualmente conseguiram acréscimo da rizogênese de estacas apicais de figueira com a utilização de $2.000 \mathrm{mg} \mathrm{L}^{-1} \mathrm{AIB}$, em comparação ao controle (sem AIB).

Maiores diferenças entre a ausência e o tratamento com AIB na percentagem de enraizamento foram detectadas nas estacas não estratificadas, com incremento de $45 \%$ de enraizamento. Nas estacas com tratamento de estratificação, o incremento com a aplicação do AIB variou de 10 a 25\%, comprovando-se o aumento da rizogênese dos propágulos de figueira com a exposição a baixas temperaturas.

A melhoria da rizogênese das estacas apicais submetidas à exposição a baixas temperaturas foi detectada tanto na ausência, quanto na presença de AIB. Estacas estratificadas por 45 dias e sem tratamento com AIB apresentaram $90 \%$ de enraizamento, $70 \%$ a mais que a testemunha.
Por sua vez, nas estacas que receberam tratamento com a referida auxina, ocorre enraizamento de $100 \%$ para as estratificadas por 15 e 45 dias, incremento de 35\% em relação à testemunha sem estratificação (Tabela 1). Comparando-se esses resultados com os resultados obtidos por Pio et al. (2006a), que obtiveram 57\% de enraizamento em estacas apicais tratadas com $2.000 \mathrm{mg} \mathrm{L}^{-1}$ de AIB, a estratificação a frio úmido incrementou em $43 \%$ o enraizamento das estacas.

Na ausência de tratamento com AIB, o número máximo de raízes por estaca ocorreu nas estacas estratificadas por 30 e 45 dias (13,25 e 17,25 raízes por estaca, respectivamente). Porém, estacas estratificadas a frio úmido por 30 dias e sequencialmente tratadas com AIB apresentaram média de 83 raízes por estaca, mais de 50 raízes a mais que as estacas não estratificadas e tratadas com AIB. O aumento desse número é benéfico no posterior transplante das estacas para as sacolas plásticas, minimizando danos em decorrência de possíveis quebras de raízes na operação de transplantio e ainda refletindo positivamente no desenvolvimento da muda.

Os resultados obtidos na rizogênese dos propágulos oriundos da porção apical dos ramos lenhosos de figueira Roxo de Valinhos estão de acordo com os obtidos por Pio et al. (2004), que anteriormente fizeram referência ao potencial de utilização das estacas apicais para a produção de mudas de figueira. Os resultados em percentuais de rizogênese obtidos no presente trabalho (Tabela 1) são superiores àqueles obtidos por Pio et al. (2006a), que obtiveram 56,67\% de enraizamento e média de 16,13 raízes por estaca com o uso de $2.000 \mathrm{mg} \mathrm{L}^{-1}$ de AIB.

Quanto ao desenvolvimento das brotações nas estacas apicais, houve incremento de $40 \%$ de brotação para as estacas tratadas com AIB em relação às não-tratadas (Tabela 2). Esse resultado é reflexo da rizogênese ocorrida nas estacas, uma vez que os resultados são similares aos obtidos para a percentagem de enraizamento. No entanto, efeitos positivos foram detectados com a estratificação das estacas a frio úmido, tanto para as tratadas como para

Tabela 1. Percentagem de estacas enraizadas e número médio de raízes de estacas apicais de figueira Roxo de Valinhos (Ficus carica L.) submetidas à estratificação a frio úmido e tratadas e não-tratadas com $2.000 \mathrm{mg} \mathrm{L}^{-1}$ de AIB.

\begin{tabular}{|c|c|c|c|c|c|c|c|c|}
\hline \multirow{3}{*}{$\begin{array}{l}\text { Tempo de } \\
\text { estratificação (dias) } \\
\\
\text { Controle }\end{array}$} & \multicolumn{4}{|c|}{ Estacas enraizadas (\%) } & \multicolumn{4}{|c|}{$\mathrm{N}^{0}$ médio de raízes/estaca } \\
\hline & \multicolumn{2}{|c|}{ Sem AIB } & \multicolumn{2}{|c|}{$\begin{array}{c}\text { Com AIB } \\
\left(2.000 \mathrm{mg} \mathrm{L}^{-1}\right)\end{array}$} & \multicolumn{2}{|c|}{ Sem AIB } & \multicolumn{2}{|c|}{$\begin{array}{c}\text { Com AIB } \\
\left(2.000 \mathrm{mg} \mathrm{L}^{-1}\right.\end{array}$} \\
\hline & 20,0 & $\mathrm{Bd}$ & 65,0 & $\mathrm{Ab}$ & 4,50 & $\mathrm{Bb}$ & 32,75 & Ad \\
\hline 15 & 77,5 & $\mathrm{Bb}$ & 100,0 & Аа & 6,00 & $\mathrm{Bb}$ & 48,75 & $\mathrm{Ab}$ \\
\hline 30 & 75,0 & $\mathrm{Bb}$ & 100,0 & Aa & 13,25 & $\mathrm{Ba}$ & 83,00 & Aa \\
\hline 45 & 90,0 & $\mathrm{Ba}$ & 100,0 & Aa & 17,25 & $\mathrm{Ba}$ & 38,50 & Ac \\
\hline 60 & 60,0 & $\mathrm{Bc}$ & 75,0 & $\mathrm{Ab}$ & 8,50 & $\mathrm{Bb}$ & 40,33 & Ac \\
\hline C.V. (\%) & \multicolumn{4}{|c|}{8,98} & \multicolumn{4}{|c|}{12,22} \\
\hline
\end{tabular}

${ }^{1}$ Médias seguidas da mesma letra maiúscula na linha e minúscula na coluna não diferem entre si, pelo teste Scott-Knott, a 5\% de probabilidade. 
Tabela 2. Percentagem de estacas brotadas e número médio de brotos de estacas apicais de figueira Roxo de Valinhos (Ficus carica L.) submetidas à estratificação a frio úmido e tratadas e não-tratadas com $2.000 \mathrm{mg} \mathrm{L}^{-1}$ de AIB.

\begin{tabular}{|c|c|c|c|c|c|c|c|}
\hline \multirow{3}{*}{$\begin{array}{l}\text { Tempo de } \\
\text { estratificação (dias) } \\
\end{array}$} & \multicolumn{3}{|c|}{ Estacas brotadas (\%) } & \multicolumn{4}{|c|}{$\mathrm{N}^{0}$ médio de brotos/estaca } \\
\hline & \multicolumn{2}{|c|}{ Sem AIB } & $\begin{array}{c}\text { Com AIB } \\
\left(2.000 \mathrm{mg} \mathrm{L}^{-1}\right)\end{array}$ & \multicolumn{2}{|c|}{ Sem AIB } & \multicolumn{2}{|c|}{$\begin{array}{c}\text { Com AIB } \\
\left(2.000 \mathrm{mg} \mathrm{L}^{-1}\right)\end{array}$} \\
\hline & 27,5 & $\mathrm{Bb}$ & $67,5 \mathrm{Ab}$ & 1,37 & $\mathrm{Bb}$ & 1,95 & $\mathrm{Ab}$ \\
\hline 15 & 90,0 & $\mathrm{Aa}$ & 100,0 Аа & 1,90 & $\mathrm{Bb}$ & 2,22 & $\mathrm{Ab}$ \\
\hline 30 & 90,0 & Aa & 100,0 Аа & 1,87 & $\mathrm{Bb}$ & 2,87 & Аа \\
\hline 45 & 92,5 & Аа & 100,0 Аа & 2,47 & Aa & 2,22 & $\mathrm{Ab}$ \\
\hline 60 & 82,5 & Aa & 90,0 Аа & 1,75 & $\mathrm{Ab}$ & 2,00 & $\mathrm{Ab}$ \\
\hline C.V. (\%) & \multicolumn{3}{|c|}{9,77} & \multicolumn{4}{|c|}{14,36} \\
\hline
\end{tabular}

${ }^{1}$ Médias seguidas da mesma letra maiúscula na linha e minúscula na coluna não diferem entre si, pelo teste Scott-Knott, a 5\% de probabilidade.

as não-tratadas com AIB. Nas estacas que receberam o tratamento com AIB, todas aquelas estratificadas apresentaram mais de $90 \%$ de brotação, pelo menos $22,5 \%$ a mais que a testemunha não-estratificada. Conforme relata Biasi (1996), a técnica de estratificação das estacas em baixa temperatura supre a necessidade intrínseca de frio dos propágulos das frutíferas de clima temperado, superando a endodormência das gemas e, consequentemente, promovendo a brotação.

No número médio de brotos houve diferença estatística apenas para estacas estratificadas por até 30 dias e tratadas e não tratadas com AIB. Quanto à estratificação, melhores resultados foram obtidos com as estacas estratificadas por 45 dias e não tratadas com AIB (2,47 brotos/estaca) e estratificadas por 30 dias e tratadas com AIB (2,87 brotos/estaca) (Tabela 2). Observa-se que, em média, o número de brotos em todos os tratamentos foi superior a um broto por estaca, o que concorda com o obtido por Pio et al. (2006b).

\section{CONCLUSÃO}

Estacas apicais de figueira Roxo de Valinhos estratificadas a frio úmido por 30 dias e posteriormente tratadas com $2.000 \mathrm{mg} \mathrm{L}^{-1}$ de AIB possuem elevada capacidade rizogênica e favorecem a produção de mudas de figueira.

\section{REFERÊNCIAS}

Alvarenga AA, Abrahão E, Fraguas JC, Carvalho VL, Silva RA, Santa Cecilia LVC, Cunha RL \& Silva VJ (2007) Figo (Ficus carica L.). In: Trazilbo JPJ \& Madelaine V (Eds.). 101 Culturas - Manual de tecnologias agrícolas. Belo Horizonte, EPAMIG. p.365-372.

Biasi LA (1996) Emprego do estiolamento na propagação de plantas. Ciência Rural, 26:309-315.

Chalfun NNJ \& Hoffmann A (1997) Propagação da figueira. Informe Agropecuário, 18:9-13.

Fachinello JC, Hoffmann A \& Nachtigal JC (2005) Propagação de plantas frutíferas. Brasília, Embrapa. 221p.
Gonçalves FC, Chalfun NNJ, Alvarenga AA \& Miranda CS (2003) Influência da forma de acondicionamento sob frio na sobrevivência de mudas de figueira. Ciência e Agrotecnologia, 27:798-803.

Pio R, Ramos JD, Chalfun NNJ, Coelho JHC, Gontijo TCA, Carrijo EP \& Villa F (2004) Enraizamento adventícios de estacas apicais de figueira e desenvolvimento inicial das plantas no campo. Ciência e Agrotecnologia, 28:215-221.

Pio R, Ramos JD, Chalfun NNJ, Gontijo TCA, Mendonça V, Carrijo EP \& Chagas EAa (2006a) Propagação de estacas apicais de figueira: diferentes ambientes, ácido indolbutírico e tipo de estaca. Ciência e Agrotecnologia, 30:1021-1026.

Pio R, Chagas EA, Barbosa W, Mendonça V, Scarpare Filho JA \& Guimaraes VF (2006b) Enraizamento de estacas de figueira coletadas em diferentes posições no ramo e ambientes de propagação distintos. Scientia Agrária Paranaensis, 5:1-5. 